\title{
Ecology of the Critically Endangered Kandian Torrent Toad (Adenomus kandianus) in Pidurutalagala, Sri Lanka
}

\author{
Gabadage D.E. ${ }^{1}$, Karunarathna D.M.S.S. ${ }^{2}$, Henkanaththegedara S.M. ${ }^{3}$, , Botejue \\ W.M.S. ${ }^{*}$, Madawala M.B. ${ }^{4}$ and Surasinghe T.D. ${ }^{5}$ \\ ${ }^{1}$ Biodiversity Conservation Society, Sri Lanka \\ ${ }^{2}$ Nature Explorations \& Education Team, Sri Lanka \\ ${ }^{3}$ Department of Biological \& Environmental Sciences, Longwood University, United States \\ ${ }^{4}$ South Australian Herpetology Group, South Australian Museum, Australia \\ ${ }^{5}$ Department of Biological Sciences, Bridgewater State University, United States \\ *madhavabotejue@gmail.com
}

\begin{abstract}
The stream-dwelling Sri Lankan endemic toad genus Adenomus represents two species: $A$. kelaartii and A. kandianus. The Kandian torrent toad, A. kandianus, was considered extinct until its rediscovery at Peak Wilderness sanctuary after 136 years in 2012. Currently, this species is recorded from two distinct localities in the Central highlands (1400 $\mathrm{m}$ above sea level). Red List conservation status has been re-evaluated as Critically Endangered of IUCN.

Based on transect surveys and opportunistic excursions, we conducted a 4 year study (1-weeklong survey per year during 2011-2013 and two, one-week-long surveys in 2014) to assess habitat associations, abundance, and behavior of A. kandianus in its second locality, near Pidurutalagala Conservation Forest. Surveys were conducted in the morning (07.00-14.00 hrs) and evening (18.00-20.00 hrs). Several environmental parameters were also measured to characterize the habitat preferences of the toads. Our survey revealed that the toads were associated with five microhabitats: on moss-covered in-stream boulders (most of the time, underneath leaf litter on the boulders), in-stream pools with decaying organic-matter substrate, in-stream pools with sandy substrates, riffles with rocky-cobble-pebble substrate, and within undercut banks with leaf litter and complex root structure of riparian vegetation. We recorded a total of 169 individuals which related to an average of 24.5 males, 13 females, and 6.75 juveniles per year. Presence of toads were limited to the stream channel, including undercut banks, and absent in the woodlands. Perching was the most observed behavior among males followed by mating. Among females, mating was the most dominant behavior. Juveniles were mostly observed in their under bank refugee while on limited instances, they emerged onto the river banks. The juveniles had partially-developed webbing in their feet, thus were weak swimmers. Adults had complete webbing, thus were strong swimmers and swam perpendicular to the flow.

Anthropogenic activities, such as intensive crop-farming deterred these species; proximity to croplands was a strong negative impact on species abundance. We recommend re-delineation of both the core habitat and the buffer zone of Pidurutalagala Conservation Forest so that the toad habitat can be incorporated into the reserve to limit the impacts of human activities on this population.
\end{abstract}

Keywords: Amphibian, Behavior, Conservation, Extinct, Montane forest, Threats

Proceedings of the International Forestry and Environment Symposium 2016, Department of Forestry and Environmental Science, University of Sri Jayewardenepura, Sri Lanka. 